\title{
OPERATIONS OF A SHARED, AUTONOMOUS, ELECTRIC VEHICLE FLEET: IMPLICATIONS OF VEHICLE \& CHARGING INFRASTRUCTURE DECISIONS
}

\author{
T. Donna Chen \\ Assistant Professor \\ Department of Civil \& Environmental Engineering \\ The University of Virginia \\ tdchen@virginia.edu \\ Kara M. Kockelman \\ (Corresponding author) \\ E.P. Schoch Professor of Engineering \\ Department of Civil, Architectural and Environmental Engineering \\ The University of Texas at Austin \\ kkockelm@mail.utexas.edu \\ Phone: 512-471-0210 \\ Josiah P. Hanna \\ Department of Computer Science \\ The University of Texas at Austin \\ jphanna@cs.utexas.edu
}

\begin{abstract}
There are natural synergies between shared autonomous vehicle (AV) fleets and electric vehicle (EV) technology, since fleets of AVs resolve the practical limitations of today's non-autonomous EVs, including traveler range anxiety, access to charging infrastructure, and charging time management. Fleet-managed AVs relieve such concerns, managing range and charging activities based on real-time trip demand and established charging-station locations, as demonstrated in this paper. This work explores the management of a fleet of shared autonomous (battery-only) electric vehicles (SAEVs) in a regional discrete-time, agent-based model. The simulation examines the operation of SAEVs under various vehicle range and charging infrastructure scenarios in a gridded city modeled roughly after the densities of Austin, Texas.
\end{abstract}

Results based on 2009 NHTS trip distance and time-of-day distributions indicate that fleet size is sensitive to battery recharge time and vehicle range, with each 80 -mile range SAEV replacing 3.7 privately owned vehicles and each 200-mile range SAEV replacing 5.5 privately owned vehicles, under Level II (240-volt AC) charging. With Level III 480-volt DC fast-charging infrastructure in place, these ratios rise to 5.4 vehicles for the 80 -mile range SAEV and 6.8 vehicles for the 200-mile range SAEV. SAEVs can serve 96 to $98 \%$ of trip requests with average wait times between 7 and 10 minutes per trip. However, due to the need to travel while "empty" for charging and passenger pick-up, SAEV fleets are predicted to generate an additional 7.1 to $14.0 \%$ of travel miles. Financial analysis suggests that the combined cost of charging infrastructure, vehicle capital and maintenance, electricity, insurance, and registration for a fleet of SAEVs ranges from $\$ 0.42$ to $\$ 0.49$ per occupied mile traveled, which implies SAEV service can be offered at the equivalent per-mile cost of private vehicle ownership for low mileage 
households, and thus be competitive with current manually-driven carsharing services and significantly cheaper than on-demand driver-operated transportation services. When Austinspecific trip patterns (with more concentrated trip origins and destinations) are introduced in an additional case study, the simulation predicts a decrease in fleet "empty" vehicle-miles (down to 3 to 4 percent of all SAEV travel) and average wait times (ranging from 2 to 4 minutes per trip), with each SAEV replacing 5 to 9 privately owned vehicles.

\section{KEYWORDS}

Agent-based modeling, carsharing, electric vehicles, autonomous vehicles.

\section{INTRODUCTION}

Recent transportation trends in increasing electric vehicle (EV) sales and growing carsharing membership have important impacts on greenhouse gas emissions and energy use. Incentivizing plug-in EV adoption and shared-vehicle use may be key strategies for helping regions achieve national- and state-level air quality standards for ozone and particulate matter, and ultimately carbon-emissions standards. At the same time, with the rise of the shared-use economy, carsharing is emerging as an alternative mode that is more flexible than transit but less expensive than traditional private-vehicle ownership. However, the growth of EVs and carsharing are both hindered by technological and social factors. For EVs, the most significant hindrance may be "range anxiety," a user's concern for being stranded with a fully discharged battery and no reasonable recharge option (Bartlett 2012). Meanwhile, as EVs penetrate the private and commercial vehicle fleets, they are also gaining ground in the carsharing world. EVs are a natural match for carsharing operations as existing members of carsharing operations tend to drive smaller and more fuel efficient vehicles than non-carshare members (Martin and Shaheen 2011). Cutting edge carsharing operators (CSOs) are already employing EVs in their fleets (such as Daimler's Car2Go and BMW's DriveNow operations), but the manual relocation of fleets in one-way carsharing systems continues to present profitability challenges to CSOs. The introduction of autonomous driving technology would remove the challenge of manual vehicle relocation and presents a driver-free method for shared EVs to reach travelers' origins and destinations as well as charging stations. In a carsharing setting, a fleet of shared autonomous electric vehicles (SAEVs) would automate the battery management and charging process, and take range anxiety out of the equation for growth of EVs. With the recent popularity of ondemand transportation services through transportation network companies, it is possible to imagine a future travel system where autonomous vehicle (AV) technologies merges with carsharing and EVs in a SAEV fleet. But can self-driving vehicles be shared, self-charged, and right (battery-) sized for the trip lengths that travelers desire?

This study attempts to answer this question through the simulation of a SAEV fleet in a discretetime agent-based model, examining fleet operations in a 100-mile by 100-mile gridded metropolitan area. Scenarios combine short-range and long-range electric vehicles with Level II and Level III charging infrastructure to look at the impacts of vehicle range and charging time on fleet size, charging station sites, ability to meet trip demand, user wait times, and induced vehicle miles traveled (VMT). Following the discussion of the simulation results, a financial analysis highlights the tradeoffs between capital investment in vehicles and charging infrastructure and user benefits. 


\section{PRIOR RESEARCH}

There is a wealth of literature examining carsharing, electric vehicles and charging infrastructure planning, and autonomous vehicles as separate topics. Studies looking at gasoline-propelled and (especially) electric AVs in a shared setting are more limited. Wang et al. (2006) proposed a dynamic fleet management algorithm for shared fully automated vehicles based on queuing theory. In a simulative environment with five stations and five vehicles, the average passenger waiting time was 3.37 minutes with average vehicle usage rate of 4.3 vehicles, compared to a fixed dispatch algorithm where average passenger wait time was 4.89 minutes and vehicle usage rate 3.7 vehicles. Spieser et al. (2014) modeled a fleet of shared self-driving vehicles in Singapore in the absence of any private vehicles, and found that each shared vehicle can replace three privately owned vehicles and serve 12.3 households. In Kornhauser et al. (2013), aTaxiStands (autonomous taxi stands) are placed in every half mile by half mile pixel across New Jersey, and passengers walk to taxi stands rather than allowing AVs to relocate. Douglas (2015) uses the base model proposed in Kornhauser et al. (2013) to size the fleet of an autonomous taxi system in a 5-mile by 5-mile subset of the New Jersey model and found a minimum of 550 vehicles was needed to serve the trip demand. Burns et al. (2013) examined the performance of a shared autonomous fleet in three distinct city environments: a mid-sized city (Ann Arbor, Michigan), a low-density suburban development (Babcock Ranch, Florida), and a large densely-populated urban area (Manhattan, New York). The study found that in mid-sized urban and suburban settings, each shared vehicle could replace 6.7 privately owned vehicles. Meanwhile, in the dense urban setting, the current taxi fleet could be downsized by $30 \%$ with the introduction of autonomous driving technology with average wait times at less than one minute. The International Transport Forum (2015) looked at the application of shared and self-driving vehicles in Lisbon, Portugal, and found that with ride-sharing enabled, each shared vehicle can replace approximately 10 privately owned vehicles and induces $6 \%$ more VMT than the current baseline. Without ride-sharing, each sequentially shared vehicle can replace 6 privately owned vehicles but induces $44 \%$ more travel distance. This study also looked at the impact of electrifying shared self-driving vehicles, assuming an electric range of 175 kilometers (108 miles) and a recharge time of 30 minutes, and found that the fleet would need to be $2 \%$ larger. Fagnant and Kockelman (2014) presented an agent-based model for Shared Autonomous Vehicles (SAVs) which simulated environmental benefits of such a fleet as compared to conventional vehicle ownership and use in a dense urban core area. Simulation results indicated that each SAV can replace 11 conventional private owned vehicles, but generates up to $10 \%$ more travel distances. When the simulation was extended to a case study of low market penetration (1.3\% of trips) in Austin, Texas, each SAV was found to be able to replace 9 conventional vehicles and on average, generated 8\% more VMT due to unoccupied travel (Fagnant et al. 2015).

Charging/refueling in a fleet of shared self-driving vehicles has remained a missing component in all of the prior studies mentioned here except ITF (2015) and Fagnant and Kockelman (2014), both of which model the refueling process rather simplistically. Fagnant and Kockelman (2014) modeled the logistics of refueling by assuming the 400-mile range SAVs could refuel at any location within the grid with a fixed service lag time. In ITF (2015), recharging of EVs is only looked at in terms of equivalent fleet sizing compared to longer-range and shorter-recharge-time, gasoline-propelled vehicles. No study has examined the operations of shared autonomous vehicles looking specifically at the vehicle propulsion system and charging infrastructure, both 
134 of which have direct impacts on the vehicle's ability to travel to passengers as well as 135 fueling/charging stations. The work described here builds from the framework in Fagnant and 136 Kockelman (2014) and analyzes the operations of a SAEV fleet under different vehicle range and 137 charging infrastructure assumptions. There are natural synergies between AVs and EVs, as the 138 "smart" nature of AVs resolve the practical limitations of the non-autonomous EV in the market 139 today. These limitations include the previously discussed all electric range, charging station 140 density, and charging time management. Fleet managed "smart" AVs relieve such concerns from 141 the individual traveler, managing range and charging activities based on predicted trip demand 142 and established locations of charging stations, as demonstrated in the work here.

\section{METHODOLOGY}

147 The discrete-time agent based model used here is an expansion of the 10-mile by 10-mile model 148 proposed by Fagnant and Kockelman (2014). In its setup, the model generates a square 100-mile 149 by 100-mile gridded metropolitan area, divided into 160,000 quarter-mile by quarter-mile cells. 150 The gridded city (roughly modeled after the population density pattern of Austin, Texas) is 151 divided into four zones as shown in Figure 2-1: downtown (the innermost 2.5-mile radius), urban 152 (the next ring 7.5-mile radius), suburban (the next ring 15-mile radius), and exurban (the 153 remainder area). Zone population densities and trip rates are determined with data from the 154 Austin travel demand model segmented by population density (see Table 1). Each zone has its 155 own unique average trip generation rate (representing approximately $10 \%$ of all trips in the 156 Austin region inclusive of return trips, reflecting what Shaheen et al. [2006] estimates as market 157 potential for carsharing in a manually-driven setting) and average peak and off-peak travel 158 speeds (derived from sample peak and off-peak trips from the Austin travel demand model), as 159 shown in Table 1. 


\section{$100 \mathrm{mi}$}

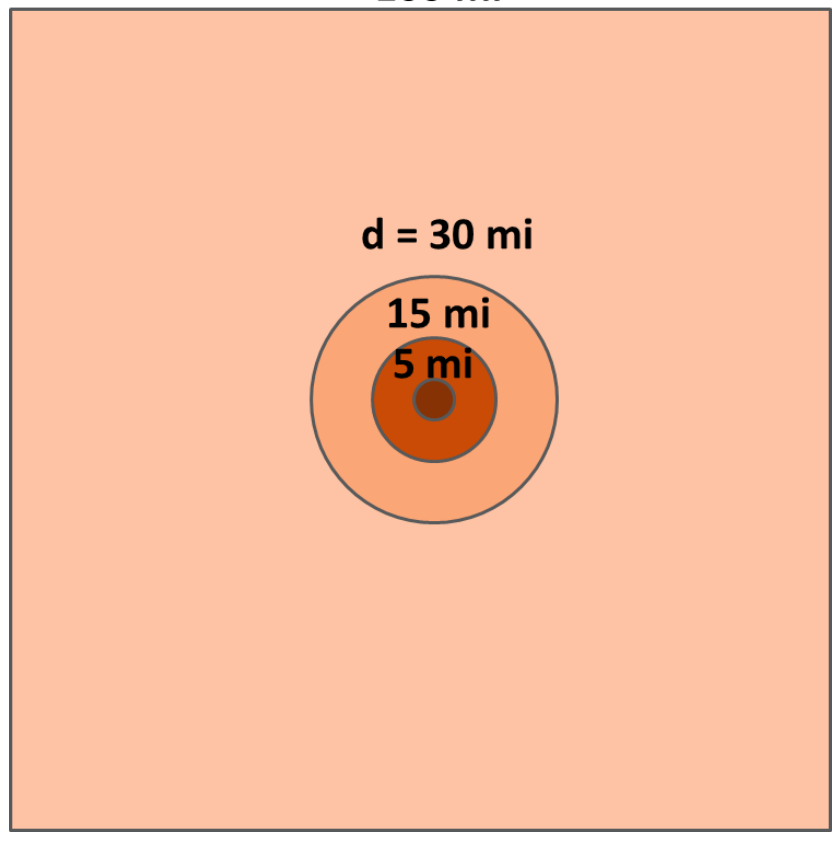

Figure 1. City Zones and Zone Limits

Table 1. Zone Trip Generation Rates \& Travel Speeds

\begin{tabular}{|l|c|c|c|c|}
\hline & Population Density & Avg Trip Gen. Rate & \multicolumn{2}{|c|}{ Travel Speed (mi/hr) } \\
\cline { 4 - 5 } & (persons/mi ${ }^{2}$ ) & (trips/cell/day) & Peak & Off-Peak \\
\hline Downtown & $7500-50,000$ & 129 & 15 & 15 \\
\hline Urban & $2000-7499$ & 39 & 24 & 24 \\
\hline Suburban & $500-1999$ & 11 & 30 & 33 \\
\hline Exurban & $<499$ & 1 & 33 & 36 \\
\hline
\end{tabular}

The actual trip generation rate in each cell is drawn from a Poisson distribution with Table 1's value used as the average rate for each 5-minute time step within a 24-hour temporal distribution following the 2009 National Household Travel Survey (FHWA 2009). The destination cells for each trip generated are assigned as a function of the trip length (drawn from the 2009 NHTS trip length distribution) and proportional to the share of cells to the north, south, east, and west of the origin cells. In other words, the trip generation methodology used here favors higher attraction levels towards the city center. In the simulation, roughly 680,000 SAEV trips are generated per 172 day (representing roughly $10 \%$ of trips in a simulated 2.9 million people region). For detailed 173 information on the step-by-step trip generation methodology used here, please refer to Fagnant 174 and Kockelman (2014).

The model first runs through a two-phase warm start, during which the number of charging stations and the size of the SAEV fleet is determined. After the warm start completes, the model then runs for 50 consecutive days with the predetermined fleet size and charging station layout to 
output fleet operation performance metrics. Each phase of the model is discussed in detail in the following sections.

\section{Charging Stations Generation}

In Phase 1 of the warm start, consecutive 24-hour days are modeled to determine the number of charging stations needed for full service of the SAEV fleet. Figure 2 demonstrates the process of how and where charging stations are generated in the warm start.

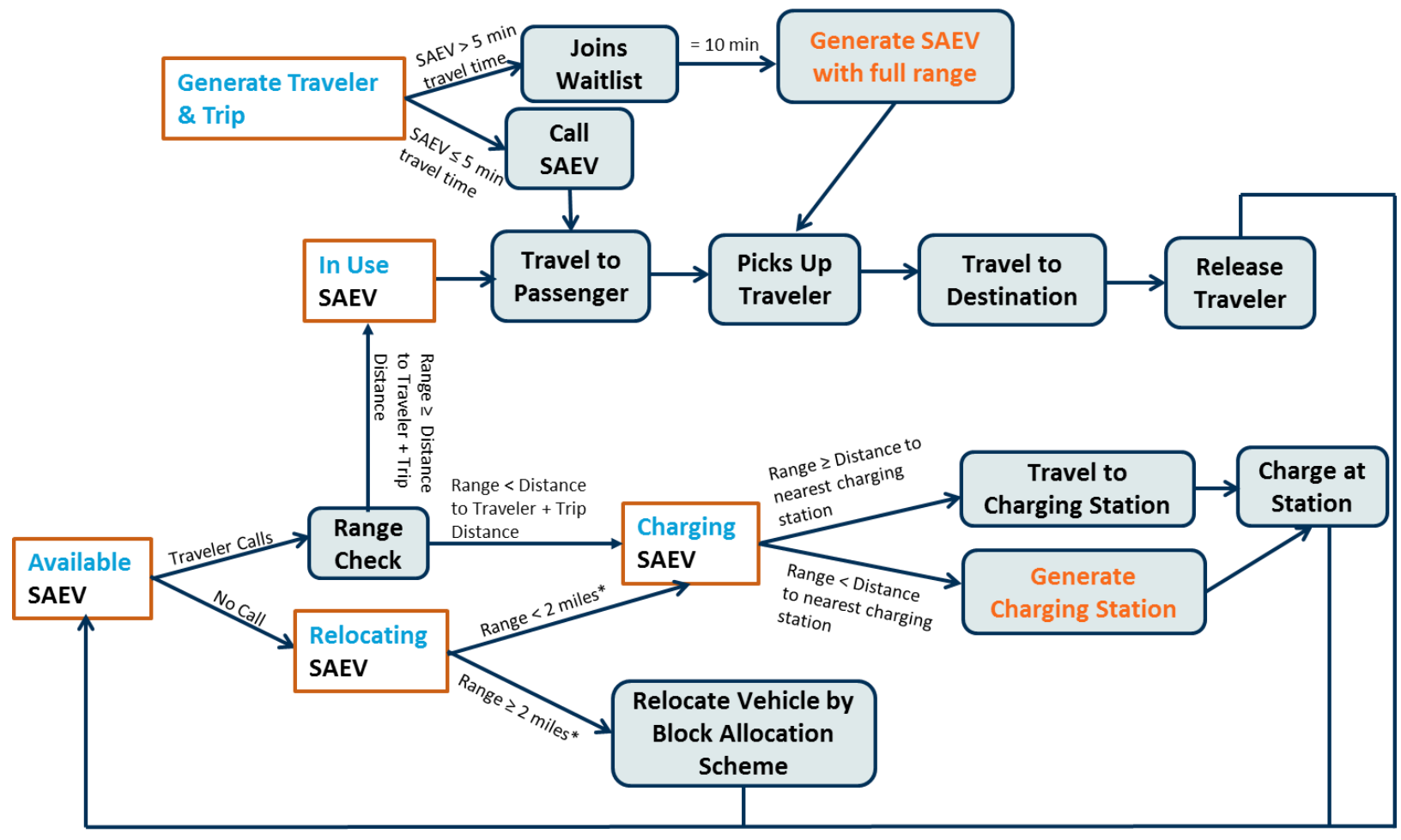

Figure 2. Agent Based Model Algorithm: Charging Station Generation

Once a trip is generated by the process discussed in the Model Setup section, a traveler looks for the closest available status SAEV within a 5-minute travel time radius through a greedy search algorithm (searching at increasing distances starting from its own origin cell). If an available SAEV is located within a 5-minute travel-time radius, the traveler claims the SAEV and the SAEV falls under in use mode for the subsequent time periods to pick up the traveler, complete the assigned trip, and release traveler. If a SAEV is not available within a 5-minute travel-time radius, the traveler joins a waitlist. In the following 5-minute time step, travelers on the wait list are prioritized and served first, before new trips generated during the current time step are served by SAEVs. When a traveler has been on the waitlist for 10 minutes (or two time steps), a new $\mathrm{SAEV}$ is generated with full charge in the traveler's origin cell.

Once a SAEV releases a traveler at the destination cell, the vehicle changes from in use to available status, and awaits for a traveler call in the subsequent 5-minute time step. If the vehicle is not called in the time step, the SAEV changes from available to relocating status, and its subsequent actions are discussed in the Strategic Vehicle Relocation section. If a traveler calls, 
the SAEV checks to ensure that its remaining range is greater than the distance to the traveler plus the distance of the requested trip before accepting the call. If the range is insufficient, the call is rejected and the SAEV changes from available to charging status. In charging status, the SAEV looks for the nearest charging station (by the same greedy algorithm used in trip matching), and if one does not exist within its remaining range, a charging station is generated in the SAEV's current cell. The SAEV then stays in charging status at the charging station for the number of time steps proportional to its remaining range to achieve full charge status, as shown in Equation 1:

$T_{\text {charge }}=\left\lceil\frac{\text { Range }_{\text {full }}-\text { Range }_{\text {current }}}{\text { Range }_{\text {full }}}\right\rceil T_{\text {full }}$

where $T_{\text {charge }}$ is the number of time steps a SAEV remains at the charging station in charging status before becoming available for the next traveler, Range $e_{f u l l}$ is the number of grid cells a SAEV can travel when fully charged, Range current is the SAEV's current remaining range, and $T_{\text {full }}$ is the number of time steps required for a fully depleted SAEV battery to fully charge. Phase 1 continues until the number of charging stations on consecutive days converges to within $1 \%$.

\section{SAEV Fleet Generation}

When Phase 1 is complete, the charging station layout is set and no more charging stations can be added to the city. The SAEV fleet is cleared to start Phase 2, which determines the size of the SAEV fleet. The two phases of the warm start operate independently of each other since the number of SAEVs required in the fleet depends on the number of charging stations available. During the generation of the charging stations, the corresponding SAEV fleet is (temporarily) oversized. The overall algorithm for Phase 2 is similar to that of Phase 1. However, because no charging stations are generated in Phase 2, in order to accept a traveler's call, the SAEV must have sufficient range to travel to the traveler, complete the requested trip, and travel to the nearest charging station from the destination cell. Phase 2 is run for 20 days, with vehicles cleared at the end of each day. The average number of SAEVs generated from the 20 days is taken as the fleet size for the full run.

\section{Waitlist}

Once the charging station locations and SAEV fleet size is determined from the two-phase warm start, the program runs through 50 consecutive days when vehicles are in continuous operation (no vehicle clearing). The full run's model structure is identical to that of Phase 2, except no new SAEVs are generated and travelers remain on the waitlist. If a traveler's trip request is rejected in 6 consecutive time steps (equivalent to 30 minutes on the waitlist), that trip is considered unserved and is removed from the waitlist.

\section{Strategic Vehicle Relocation}

During each step of the model (warm start and full run), available SAEVs that are not called by travelers are assigned to relocating status for that time step. The relocation strategy used in this model first attempts to balance the available SAEVs in the current time step with the expected 
demand in a 2-mile by 2-mile block in the subsequent time step, then uses two additional strategies to efficiently distribute SAEVs amongst bordering blocks with a large vehicle supply gap. This combination of relocation strategies was deemed the most effective out of several that were tested in Fagnant and Kockelman (2014), which also describes the relocation process in detail. To ensure that vehicles in relocating status have sufficient range for relocation, a check ensures that the SAEV has sufficient range to travel a distance equivalent to 5 minutes of travel time from its original cell (roughly equivalent to 2 miles but varies slightly with zone) plus the distance to the nearest charging station to the relocation destination.

\section{MODEL SCENARIO RESULTS}

The agent-based model described here is run for several scenarios to examine the sensitivity of various fleet operation metrics to model inputs, as shown in Table 2. A non-electric SAV scenario (assuming 400-mile range and 15 minute refueling time) is run as a reference case for comparison to the results in Fagnant and Kockelman (2014). Next, the SAEV scenario assumes the vehicle has an 80-mile range (similar to current models of the Nissan Leaf, Chevrolet Spark, Honda Fit EV, and BMW i3) and 4 hour recharge time, corresponding to charging times of current market BEVs with a 240-volt AC Level II charger. A SAEV Fast Charge scenario combines the same 80-mile vehicle with a recharge time of 30 minutes, mimicking the specifications of current market BEVs with a Level III 480-volt DC high-current charger. Following fast charging guidelines, the SAEVs in the fast charge scenarios will only be charged to $80 \%$ full to protect the batteries from losing capacity with repeat fast charging, which effectively reduces the range to 64 miles. The last two scenarios looks at various types of charging in combination with long-range BEVs (LR SAEV) matching the 200-mile range specification of the upcoming Chevrolet Bolt and Tesla Model 3 (both with 2017 planned release dates). The LR SAEV scenario combines a 200-mile range with a 4-hour recharge time while the LR SAEV Fast Charge scenario combines a 160-mile effective range with a 30 minute fast charge time.

Table 2. Scenario Results

\begin{tabular}{|l|r|r|r|r|r|}
\hline \multicolumn{1}{|c|}{ Scenario } & SAV & SAEV & $\begin{array}{c}\text { SAEV } \\
\text { Fast Charge }\end{array}$ & LR SAEV & $\begin{array}{c}\text { LR SAEV } \\
\text { Fast Charge }\end{array}$ \\
\hline Range (mi) & 400 & 80 & 64 & 200 & 160 \\
\hline Refuel/Recharge Time (min) & 15 & 240 & 30 & 240 & 30 \\
\hline \# of Charging/Fueling Station Sites & 1062 & 1562 & 1573 & 1555 & 1517 \\
\hline \# of Chargers/Fuel Pumps* & 2245 & 30,129 & 16,510 & 16,554 & 2389 \\
\hline Fleet Size & 29,939 & 57,279 & 39,593 & 41,179 & 31,859 \\
\hline Avg Daily Miles per Vehicle & 259 & 131 & 197 & 190 & 241 \\
\hline Avg Daily Trips per Vehicle & 22.3 & 11.4 & 16.9 & 16.3 & 20.8 \\
\hline Private Veh Replacement Rate & 7.32 & 3.73 & 5.53 & 5.33 & 6.82 \\
\hline \% Trips Unserved & $2.13 \%$ & $3.94 \%$ & $4.36 \%$ & $2.29 \%$ & $2.73 \%$ \\
\hline Avg Trip Distance (mi) & 10.1 & 9.41 & 9.08 & 10.0 & 10.0 \\
\hline Avg Wait Time Per Trip (min) & 9.3 & 8.1 & 7.7 & 8.4 & 9.5 \\
\hline Avg Range Remain. at Recharge (mi) & 1.6 & 43.1 & 40.7 & 5.4 & 2.5 \\
\hline
\end{tabular}




\begin{tabular}{|l|r|r|r|r|r|}
\hline \% Total Unoccupied Travel Distance & $6.6 \%$ & $10.7 \%$ & $14.0 \%$ & $7.1 \%$ & $7.1 \%$ \\
\hline \% Unoccupied Travel for Trips & $5.2 \%$ & $4.1 \%$ & $3.0 \%$ & $4.7 \%$ & $4.9 \%$ \\
\hline \% Unoccupied Travel for Charging & $0.3 \%$ & $2.5 \%$ & $5.0 \%$ & $0.6 \%$ & $0.7 \%$ \\
\hline \% Unoccupied Travel for Relocation & $1.1 \%$ & $4.1 \%$ & $6.1 \%$ & $1.9 \%$ & $1.4 \%$ \\
\hline $\begin{array}{l}\text { Max \% Concurrently Charging } \\
\text { Vehicles }\end{array}$ & $7.5 \%$ & $52.6 \%$ & $41.7 \%$ & $40.2 \%$ & $7.5 \%$ \\
\hline
\end{tabular}

*As proxied by the maximum number of concurrent charging/refueling vehicles in the day.

Simulation results show that the number of vehicles needed in a fleet is highly sensitive to charge time and, to a slightly lesser degree, vehicle range. Substituting Level III in place of Level II chargers for SAEV and LR SAEV fleets reduced the required fleet size by 30.9 and $23.3 \%$, respectively. On the other hand, increasing the electric range of vehicles from 80 to 200 miles reduced the fleet size by 28.1 and $19.5 \%$ respectively for Level II and Level III charging schemes. Combining these effects, the necessary fleet for the SAEV scenario is almost double the size of that for the LR SAEV Fast Charge scenario. Using 2009 NHTS rates for 3.02 private car trips per licensed U.S. driver and 0.99 household vehicles per licensed driver (Santos et al. 2011), the private vehicle replacement rate is highest at one shared vehicle for every 7.3 private vehicles in the SAV scenario, in line with the results from the mid-sized urban and suburban models in Burns et. al (2013) and the regional model in Fagnant and Kockelman (2015). However, once the fleet is electrified, the private vehicle replacement rate ranges from a comparable 1:6.8 vehicle ratio in the LR SAEV Fast Charge scenario to a much lower 1:3.7 vehicle ratio in the SAEV scenario. Non-electric SAV fleet requires the fewest number of vehicles $(29,939)$ for full service, and the closest competitive EV scenario (LR SAEV Fast Charge) increases that fleet size by $6.6 \%$, a slightly larger difference than estimated in ITF (2015) despite longer EV range assumption. As seen in Figure 3, a snap shot of each vehicle's activity during the peak 5-minute period (defined as the time step with the most in use vehicles) demonstrates that with longer charging times and shorter ranges, vehicles are simply tied up at charging stations not able to service trip demand. While the number of in use vehicles is relatively consistent across all scenarios, the number of charging vehicles increases significantly with longer vehicle charge times and shorter electric range. 


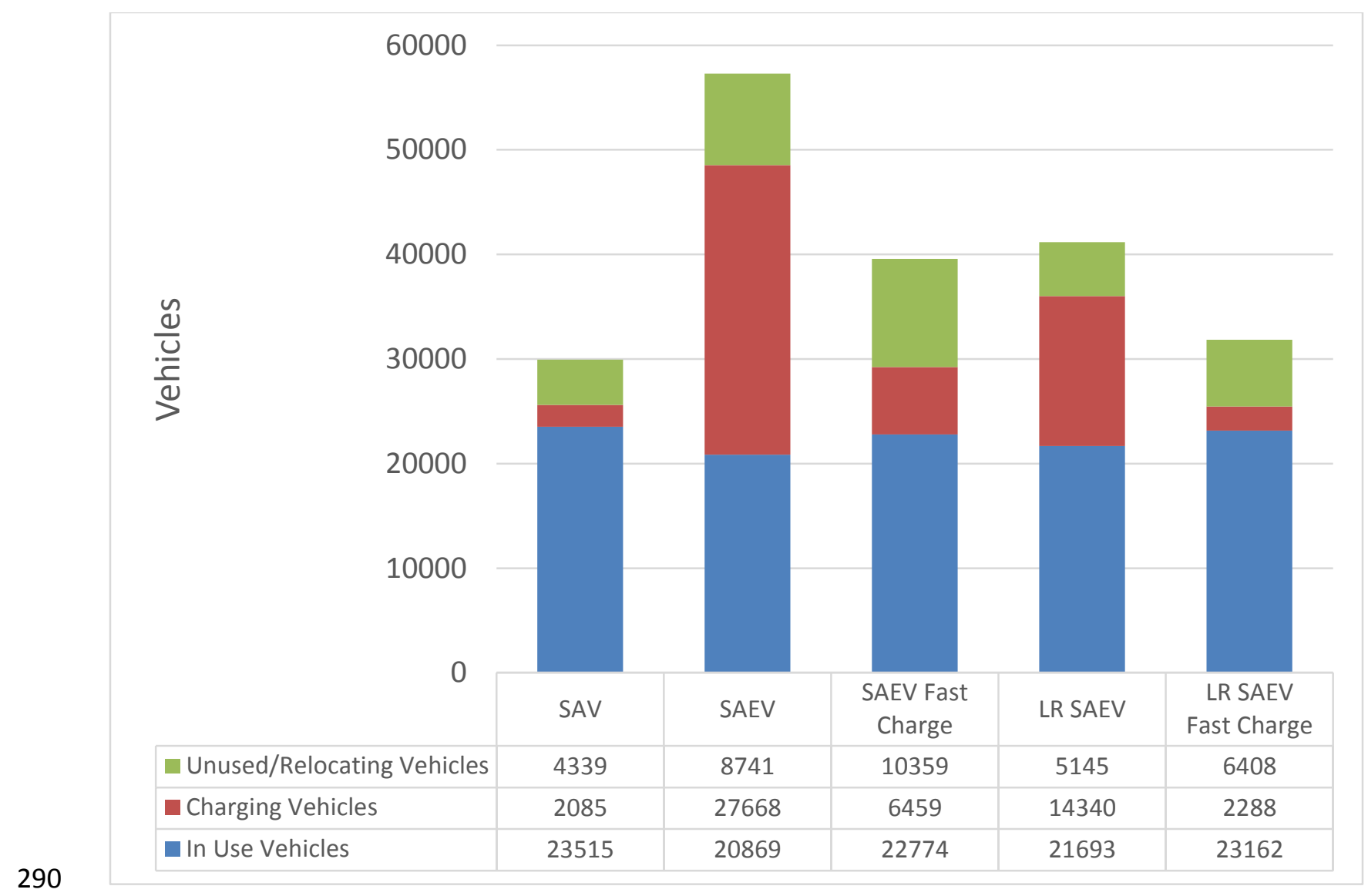

Figure 3. Peak (5-Minute) Period Vehicle Use

292 As seen in the results in Table 2, for full service, all EV scenarios produced similar numbers of charging station sites. This result suggests that the number of charging station sites (cells with charging stations) necessary for full service has an inelastic relationship with the vehicle's electric range, but is more determined by the geography of the city (or size of the service geofence). Conversely, the total number of chargers needed (as proxied by the average number of charging vehicles in the time step with the most concurrent charging across 50 days) is highly sensitive to charge time and vehicle range. Using Level III chargers cuts the charge time for SAEV and LR SAEV fleets by $87.5 \%$, and correspondingly, the number of needed chargers by 45.2 and $85.6 \%$. Holding charging infrastructure constant, substituting LR SAEVs for SAEVs in the fleet (and increasing vehicle range by $150 \%$ ), the number of chargers needed decreases 45.0 and $85.6 \%$. Generally speaking, high trip demand periods coincide with high charging activity periods. Simulation results suggest that the LR SAEV Fast Charge scenario is best at spreading out charging demand across the day, with a maximum of $7.46 \%$ of vehicles in the fleet concurrently charging during any time step. On the other hand, in the base SAEV scenario, as many as $52.6 \%$ of the vehicle fleet charge concurrently during the peak charge time period of the day (defined as the 5-minute period with the largest percentage of charging vehicles).

Simulation results show that longer vehicle range translates into higher percentages of trips $1.05 \%$ of the trips are over 80 miles long. In the simulation results, the difference between trips 
served between the 200-mile LR SAEV and the 80-mile SAEV is 1.65\%. However, longer vehicle range is generally associated with longer wait times in the simulation results, primarily due to the inefficiency of serving trips originating in low-demand suburban and exurban areas a shared setting. As seen in Table 2, longer-range vehicles spend more of their "empty" VMT for passenger pick-up while shorter-range vehicles spend more of their "empty" VMT for relocation.

Each autonomous driving scenario produced an additional 7.1 to $14.0 \%$ of unoccupied VMT, in line with estimates in ITF (2015) and Fagnant et al. (2015). As seen in Table 2, for vehicles with longer range (SAVs and LR SAEVs), the greatest portion (65.6 to $78.4 \%$ ) of that induced travel can be attributed to unoccupied vehicles traveling to pick up passengers. Unoccupied travel to charging/refueling stations played a relatively minor role in inducing additional VMT, summing to 0.5 to $0.7 \%$ of total VMT (or 4.5 to $10.0 \%$ of "empty" miles traveled) for longer range vehicles, as seen in Figure 4. Due to the more frequent need to recharge, induced miles traveled for recharging is greater for scenarios with shorter range vehicles. SAEVs registered an additional 2.5 to $5.0 \%$ miles for charging activity, consisting of 23.6 to $35.4 \%$ of their total "empty" miles traveled.

Not only do shorter range vehicles charge more frequently, simulation results in Table 2 also show that they utilize a smaller percent of their range before a charging event. The phenomenon of shorter-range vehicles recharging with higher baseline remaining range can be attributed to the demand-based charging strategy employed here, where a vehicle is assigned to charging status after rejecting a trip request due to insufficient range. With shorter ranges, the SAEVs are more frequently assigned to charging status due to increased probability of having insufficient range for trips. To explore whether charging less frequently would improve the fleet performance of the shorter range SAEV scenarios, scenarios incorporating both demand- (trip rejection) and distance- (maximum remaining range) based charging strategies were also run. Table 3 displays simulation results where SAEVs are assigned to charging status after the vehicle has rejected a trip due to insufficient range and met a maximum remaining range threshold. Results show that combining demand-based charging with a $75 \%$ (60-mile) maximum remaining range criteria yielded the best fleet performance metrics from a user perspective. Average wait times reduced to 7.37 minutes per trip and percent of trips unserved decreased to $1.70 \%$, competitive with the SAV scenario results in Table 2. From the operator perspective, applying this charging strategy increases the necessary fleet size slightly (by $0.1 \%$ ) and decreases induced travel by $12.7 \%$. Increasingly stringent recharging distance criteria continually decreases induced VMT, primarily from reduction in relocation miles. However, as relocation miles decrease, induced miles to pick up travelers increase (and subsequently increases wait times), demonstrating the inherent tradeoffs between reducing extra VMT and enhancing user experience (as measured by wait times and percent of trips served). Scenarios with distance-only thresholds for charging were also examined, but those scenarios all yielded longer wait times than charging strategies that incorporated demand.

\begin{tabular}{|l|c|c|c|c|}
\hline & $\begin{array}{c}\text { Recharge Upon } \\
\text { Trip Rejection, } \\
\text { Max Remaining } \\
\text { Range=80 mi }\end{array}$ & $\begin{array}{c}\text { Recharge Upon } \\
\text { Trip Rejection, } \\
\text { Max Remaining } \\
\text { Range=60 mi }\end{array}$ & $\begin{array}{c}\text { Recharge Upon } \\
\text { Trip Rejection, } \\
\text { Max Remaining } \\
\text { Range=40 mi }\end{array}$ & $\begin{array}{c}\text { Recharge Upon } \\
\text { Trip Rejection, } \\
\text { Max Remaining } \\
\text { Range=20 mi }\end{array}$ \\
\hline
\end{tabular}




\begin{tabular}{|l|r|r|r|r|}
\cline { 3 - 5 } Fleet Size & 57,279 & 57,354 & 57,278 & 57,174 \\
\hline \% Trips Unserved & $3.9 \%$ & $1.7 \%$ & $3.0 \%$ & $3.4 \%$ \\
\hline $\begin{array}{l}\text { Avg Wait Time } \\
\text { (min) }\end{array}$ & 8.1 & 7.4 & 8.2 & 8.5 \\
\hline $\begin{array}{l}\text { Avg Range } \\
\begin{array}{l}\text { Remaining at } \\
\text { Recharge (mi) }\end{array}\end{array}$ & 43.0 & & & \\
\hline $\begin{array}{l}\text { Avg Trip Distance } \\
\text { (mi) }\end{array}$ & 9.5 & 22.2 & 13.2 & \\
\hline $\begin{array}{l}\text { \% Total New } \\
\text { Induced Travel }\end{array}$ & $10.7 \%$ & 9.5 & 9.5 & 9.4 \\
\hline $\begin{array}{l}\text { \% New Induced } \\
\text { Travel for Charging }\end{array}$ & $2.5 \%$ & $9.3 \%$ & $9.1 \%$ & $9.0 \%$ \\
\hline $\begin{array}{l}\text { \% New Induced } \\
\text { Travel for Relocation }\end{array}$ & $4.1 \%$ & $3.3 \%$ & $3.1 \%$ & $3.1 \%$ \\
\hline $\begin{array}{l}\text { \% New Induced } \\
\text { Travel for Trips }\end{array}$ & $4.1 \%$ & $1.9 \%$ & $1.6 \%$ & $1.5 \%$ \\
\hline
\end{tabular}

\section{FINANCIAL ANALYSIS}

352 Simulation results offer some insight into how combinations of vehicles and charging 353 infrastructure impact fleet operations, but a financial analysis is necessary to truly grasp the 354 tradeoff between additional capital investment (into vehicles with bigger batteries or more 355 expensive fast charging stations) and user benefits (measured in additional trips served or 356 decreased wait times). For each vehicle and charging station type, analysis was conducted for 357 three cost levels: low-, medium-, and high-cost scenarios, as shown in Table 4.

Table 4. Vehicle \& Charging Infrastructure Cost Assumptions

\begin{tabular}{|l|r|r|r|}
\hline & Low Cost & \multicolumn{1}{c|}{ Mid Cost } & \multicolumn{1}{c|}{ High Cost } \\
\hline Vehicle Capital & & & \\
\hline SAEV (per vehicle) & $\$ 35,000$ & $\$ 40,000$ & $\$ 55,000$ \\
\hline LR SAEV (per vehicle) & $\$ 45,000$ & $\$ 50,000$ & $\$ 80,000$ \\
\hline Replacement battery (per kWh) & $\$ 240$ & $\$ 405$ & $\$ 570$ \\
\hline Vehicle Operations & & & \\
\hline Maintenance (per mile) & $\$ 0.055$ & $\$ 0.061$ & $\$ 0.066$ \\
\hline Insurance \& Registration (per vehicle-year) & $\$ 1,280$ & $\$ 1,600$ & $\$ 1,920$ \\
\hline Electricity (per kWh) & $\$ 0.11$ & $\$ 0.13$ & $\$ 0.26$ \\
\hline Charging Infrastructure & & & \\
\hline Level II Charging (per charger) & $\$ 8,000$ & $\$ 12,000$ & $\$ 18,000$ \\
\hline Level II Annual Maintenance (per charger) & $\$ 25$ & $\$ 40$ & $\$ 50$ \\
\hline Level III Charging (per charger) & $\$ 10,000$ & $\$ 45,000$ & $\$ 100,000$ \\
\hline Level III Annual Maintenance (per charger) & $\$ 1,000$ & $\$ 1,500$ & $\$ 2,000$ \\
\hline
\end{tabular}


For vehicle capital costs, the non-autonomous SAEVs are assumed to cost from $\$ 25,000$ (similar to Mitsubishi i-Miev and Smart Fortwo Electric Drive BEVs) to $\$ 45,000$ per vehicle (approximate retail cost of BMW i3 BEV), with a most likely price of $\$ 30,000$ (comparable to Nissan LEAF and Ford Focus Electric BEVs). The non-autonomous LR SAEVs are assumed to cost between $\$ 35,000$ (projected price of the future 2017 Tesla Model 3 and Chevrolet Bolt) and $\$ 70,000$ (retail price for the current model Tesla Model S), with a most likely price of $\$ 40,000$ per vehicle as critics believe the projected pricing for LR BEVs is too optimistic (see, e.g. Anderman 2014). These vehicle costs do not consider government rebates and incentives for EV purchases. AV technology is assumed to add $\$ 10,000$ to the cost of each vehicle around the time AV technology first hits the commercial market in 2025, per estimates from IHS (2014) and Schultz (2014). To convert vehicle capital costs to a per-mile basis, each SAEV is assumed to be in operation for 231,000 miles before replacement, equivalent to the average life span of a New York City taxicab (New York City Taxi \& Limousine Commission 2014). The battery is assumed to be replaced once during the SAEV's service span (or per 115,500 miles), in line with most BEVs' 100,000-mile battery warrantees and evaluations of EV batteries (see, e.g., Knipe et al. 2003). Cost for replacement batteries (24 kWh for SAEVs and $60 \mathrm{kWh}$ for LR SAEVs) are assumed to cost between $\$ 380$ to $\$ 570$ per $\mathrm{kWh}$, per estimates from Plotkin and Singh (2009).

For vehicle operation costs, maintenance (including tires) is assumed to cost between 5.5 and 6.6 cents per mile, similar to non-autonomous vehicles (AAA 2014). Insurance and registration are assumed to be on the order of two to three times the cost of privately owned vehicles, similar to assumptions in Burns et al. (2013), which translates to $\$ 1,280$ to $\$ 1,920$ annually (AAA 2014). Per-mile fuel costs assume electricity ranges 11 to 26 cents per $\mathrm{kWh}$, with a mid-range cost of 13 cents per $\mathrm{kWh}$, the US national residential electricity average (EIA 2015). The high cost scenario allows flexibility in accommodating future variable priced electricity, a growing possibility with the introduction of smart metering technology.

For charging infrastructure, Level II chargers are assumed to cost between $\$ 8,000$ and $\$ 18,000$ each, including costs for installation, hardware, materials, labor, and administration (Chang et al. 2012, USDOE 2012). Annual maintenance cost for Level II chargers are assumed to be minimal at $\$ 25$ to $\$ 50$ per year (USDOE 2012). Level III chargers are assumed to range from $\$ 10,000$ to $\$ 100,000$, with average cost at $\$ 45,000$ per station (USDOE 2012 , New York City Taxi \& Limousine Commission 2013). This cost includes installation, hardware, materials, labor, administration, and transformer upgrades. Annual maintenance cost for Level III chargers are assumed to range from $\$ 1000$ to $\$ 2000$ (New York City Taxi \& Limousine Commission 2013). To convert charging infrastructure to a per-mile basis, the service life span of charging stations is assumed to be 10 years (Chang et al. 2012). Table 5 breaks down the cost per occupied mile of travel (costs are incurred for total miles of travel but allocated to each occupied mile of travel) for each vehicle and charging infrastructure combination in the mid-cost scenario.

Table 5. Equivalent Cost Per Occupied Mile Traveled (Mid-Cost Scenario)

\begin{tabular}{|c|c|c|c|c|}
\hline & SAEV & $\begin{array}{c}\text { SAEV } \\
\text { Fast Charge }\end{array}$ & LR SAEV & $\begin{array}{c}\text { LR SAEV } \\
\text { Fast Charge }\end{array}$ \\
\hline Vehicle \& Battery & $\$ 0.249$ & $\$ 0.250$ & $\$ 0.346$ & $\$ 0.346$ \\
\hline Vehicle Maintenance & $\$ 0.071$ & $\$ 0.071$ & $\$ 0.066$ & $\$ 0.066$ \\
\hline Insurance \& Registration & $\$ 0.038$ & $\$ 0.026$ & $\$ 0.025$ & $\$ 0.020$ \\
\hline
\end{tabular}




\begin{tabular}{|l|l|l|l|l|} 
Electricity & $\$ 0.045$ & $\$ 0.045$ & $\$ 0.042$ & $\$ 0.042$ \\
\hline Charging Station Capital & $\$ 0.015$ & $\$ 0.030$ & $\$ 0.007$ & $\$ 0.004$ \\
\hline Charging Station Maintenance & $\$ 0.000$ & $\$ 0.010$ & $\$ 0.000$ & $\$ 0.001$ \\
\hline TOTAL & $\mathbf{\$ 0 . 4 1 7}$ & $\mathbf{\$ 0 . 4 3 3}$ & $\mathbf{\$ 0 . 4 8 6}$ & $\mathbf{\$ 0 . 4 7 9}$ \\
\hline
\end{tabular}

Under the most likely mid-cost scenario, a fleet of SAEVs or LR SAEVs can be operated at an equivalent per-occupied-mile-traveled cost of $\$ 0.42$ to $\$ 0.49$. The most uncertain component of this operating cost estimate is the AV technology. While $\$ 10,000$ per vehicle is assumed in the base results in Table 5, the range of cost estimates of market-ready AV technology is large. Various sources report the cost of the retrofitted AV technology on current Google self-driving cars to range from $\$ 75,000$ to $\$ 250,000$ (Rogers 2015, Tannert 2014). Once the technology is mature, IHS (2014) estimates AV technology will cost between $\$ 3500$ to $\$ 5000$ per vehicle after 5 to 10 years on the market. Incorporating the Table 4's mid-cost figures for all other cost components, SAEV operation costs range from $\$ 0.392$ per mile when AV technology costs are $\$ 5000$ per vehicle to $\$ 0.867$ per mile when AV technology costs are $\$ 100,000$ per vehicle.

Using APTA (2013) statistics, for a transit system that serves 2.4 billion annual passenger-miles, general administration expenses (including facilities and salaries) add approximately $\$ 0.184$ to per-mile operational costs. Assuming operating margins of $10 \%$ (similar to the transportation industry average) and using mid-cost estimates from Table 4, SAEV service can be offered at roughly $\$ 0.66$ to $\$ 0.74$ per occupied mile of travel. These costs are on the low end of current manually-driven free-float carsharing services such as Car2Go, which charges roughly $\$ 0.70$ to $\$ 1.23$ per mile in Austin, Texas (assuming trips are between 2 to 10 miles and travel speeds are between 15 to $35 \mathrm{mph}$ ). Under this pricing assumption, SAEV users would pay roughly 21 to $49 \%$ of what is currently charged by transportation network companies like Uber and Lyft (whose equivalent per-mile pricing is $\$ 1.50$ to $\$ 3.18$ in Austin). In fact, these costs are competitive with AAA (2014) estimates of average costs of private vehicle ownership, which ranges from $\$ 0.40$ to $\$ 0.95$ cents per mile depending on annual mileage and vehicle type, suggesting that availability of a SAEV fleet can have significant impacts on private vehicle use (and ownership), particularly for low-mileage households.

Cost estimates in Table 5 are derived from fleet size and induced VMT estimates with a demandbased charging strategy with no maximum range restriction (Table 2). Adding a $75 \%$ maximum range restriction (Table 3) on the SAEV base scenario reduces the cost by $\$ 0.020$ per mile, yielding the most cost efficient scenario at $\$ 0.397$ per mile. It is worth noting that cost estimates are based on traditional, wired charging infrastructure. Currently, a residential Level II wireless (inductive) charger can deliver similar charge times as traditional corded units while costing approximately $\$ 2500$ more per unit (Evatran n.d.). This translates to a minimal $\$ 0.002$ to $\$ 0.003$ increase in equivalent per-mile costs for the SAEV fleets modeled here. Level III inductive chargers are not currently commercially available. If wireless charging is not available for the SAEV fleets, an alternative would be to install traditional corded charging infrastructure and hire charging station attendants at each of the 1500 some odd charging station sites. Assuming one $\$ 15$-per-hour-wage attendant per charging station site, per-occupied-mile-traveled costs in Table 5 would increase $\$ 0.077$ to $\$ 0.085$. 
While these per-mile costs are lower than current carsharing services and competitive with private car ownership, their ability to compete with a fleet of non-electric SAVs depends on the availability of wireless recharging infrastructure and government tax incentives on EV purchase prices. Assuming SAVs utilize existing gasoline stations with no additional infrastructure investment, a fleet of SAVs can be operated for $\$ 0.400$ per mile with a 231,000-mile vehicle life span, $\$ 30,000$ per SAV purchase cost (\$20,000 for vehicle, $\$ 10,000$ for AV technology), $30 \mathrm{mpg}$ fuel economy, $\$ 3.50$ per gallon gasoline price, $\$ 15$ per hour wage per service attendant per gasoline station, and the same AAA-based costs for maintenance, insurance, and registration prescribed to SAEVs. Of course, this per-mile cost is highly sensitive to gasoline prices. With EVs purchased at full price, SAEVs with wireless recharging are competitive with SAVs on a per mile basis when gasoline is at $\$ 3.50$ per gallon. With current federal tax incentives of $\$ 7500$ per EV, SAEVs become price-competitive with SAVs when gasoline is at $\$ 2.50$ per gallon. Without wireless recharging infrastructure (and using station attendants at charging sites), SAEVs purchased with the $\$ 7500$ federal tax rebate are not price-competitive with SAVs until gasoline reaches $\$ 4.69$ per gallon. Without the federal rebate, this increases to $\$ 5.70$ per gallon.

\section{AUSTIN, TEXAS CASE STUDY}

While the Poisson-based trip generation process modeled in the simulated monocentric city provides some variation in each cell's trip generation rate, actual trip rates in real-city geographies are significantly less "smooth." In exurban areas, an overall low population density is often reflected by pockets of relatively dense residential development among much larger areas of very sparse population. To offer more realism here, a case study using Austinites' year2010 trip patterns with U.S. departure time choices (varying every 5 minutes) was performed. The 5-county region's 1413 traffic analysis zones (TAZs) and personal trip tables (by origin versus destination zone) were used to appreciate the effects of real-world (spatially and demographically heterogeneous) trip-making behaviors.

Austin's 1413 TAZs were mapped onto the 400-cell by 400-cell gridded region with each TAZ's trip ends assigned to one quarter-mile by quarter-mile cells. The TAZ closest to the geographic centroid of the Austin region (as determined by the mid-point value of all TAZ centroids' longitude and latitude coordinates) was identified as the simulated region's center (cell [200, 200]). Then, each of the remaining 1412 TAZs corresponded to a cell in the simulated region by indexing the TAZ centroids' latitude and longitude coordinates relative to the city center. This process creates a "spiky" trip generation pattern, where only 1413 out of the 160,000 cells (less than $0.9 \%$ ) in the simulated region served as trip origins and destinations, rather than permitting every cell to generate (and attract trips). In reality, the 1413 TAZs in the 5-county region span across 3918 square miles, or $39.2 \%$ of the 100 -mile by 100 -mile simulated region. The charging strategy of trip rejection plus a maximum $75 \%$ remaining range was employed here, since this strategy improved fleet performance metrics (in Table 3), as compared to a charging strategy based solely on trip rejection.

Table 6 shows scenario results from the Austin case study. Despite the significantly more concentrated (spatial and temporal) patterns of trip generation in these Austin data, the average daily miles per vehicle are very close to Table 2's results, which used much smoother, simulatedtrip generation rates. However, because the average trip distance (across all ground modes, not just those by automobile, as used earlier in this paper) in the Austin case study is only 5 miles (as 
opposed to the 9 to 10 mile average trip distances in Table 2's NHTS-based results, which exclude all non-auto trips and all trips under 1 mile in distance), the daily trips per vehicle (and corresponding private vehicle replacement rates) are higher. SAEVs with Level II charging infrastructure are estimated to replace 5 private vehicles in this Austin scenario, while LR SAEVs with Level III charging infrastructure replace 9 private vehicles. Intrazonal trips are modeled as zero distance trips here, and are thus excluded from the model. This is an important result: working with trips that average almost twice as long (using the NHTS trips, which can end far outside the origin region, unlike MPO-based trip tables which end at the boundary of a region) keeps the vehicles almost twice as "busy", resulting in roughly 50 percent higher vehicle replacement rates.

Table 6. Fleet Performance Metrics from Austin Case Study Scenario

\begin{tabular}{|l|r|r|r|r|r|}
\hline \multicolumn{1}{|c|}{ Austin Scenario } & SAV & SAEV & $\begin{array}{c}\text { SAEV } \\
\text { Fast } \\
\text { Charge }\end{array}$ & LR SAEV & $\begin{array}{c}\text { LR SAEV } \\
\text { Fast } \\
\text { Charge }\end{array}$ \\
\hline Range (mi) & 400 & 80 & 64 & 200 & 160 \\
\hline Refuel/Recharge Time (min) & 15 & 240 & 30 & 240 & 30 \\
\hline \# of Charging/Fueling Station Sites & 21 & 25 & 26 & 23 & 25 \\
\hline \# of Chargers/Fuel Pumps & 1053 & 16,334 & 9889 & 8852 & 1080 \\
\hline Fleet Size & 14,802 & 26,758 & 16,772 & 21,859 & 14,750 \\
\hline Avg Daily Miles per Vehicle & 253 & 137 & 216 & 171 & 253 \\
\hline Avg Daily Trips per Vehicle & 27.4 & 15.2 & 24.2 & 18.6 & 27.5 \\
\hline Vehicle Replacement Rate & 8.98 & 5.00 & 7.95 & 6.09 & 9.02 \\
\hline \% Trips Unserved & $0.52 \%$ & $0.44 \%$ & $0.25 \%$ & $0.48 \%$ & $0.41 \%$ \\
\hline Avg Trip Distance (mi) & 5.15 & 5.13 & 5.14 & 5.14 & 5.15 \\
\hline Avg Wait Time Per Trip (min) & 3.49 & 2.86 & 3.01 & 3.15 & 3.25 \\
\hline \% Total Unoccupied Travel Distance & $3.15 \%$ & $4.03 \%$ & $4.19 \%$ & $3.25 \%$ & $3.38 \%$ \\
\hline Max \% Concurrent Charging Vehicles & $7.11 \%$ & $61.04 \%$ & $58.96 \%$ & $40.50 \%$ & $7.32 \%$ \\
\hline
\end{tabular}

*As proxied by the maximum number of concurrent charging/refueling vehicles in the day.

While the Austin trips cannot go past the 5-county regional edge or border, trips under 1 mile are included here (as long as their origin and destination zones differ). Restricting trip origins and destinations to less than 1 percent of the 100-mile by 100-mile region means higher concentrations of SAEVs in select, trip-active cells, which reduces the number of unserved trips (to less than $1 \%$ across all Austin scenarios), average wait times (to between 2 and 4 minutes), and "empty" VMT (to between 3.1 to $4.2 \%$ ). Those results are partly due to vehicles needing to travel less for next-passenger pickup, due to the heavy concentrations of trip origins and destinations.

Restricting all trips to travel between these 1413 cells also drastically reduces the number of charging station sites necessary, from 1500 some charging sites down to just 23 to 25 cells with charging stations. These charging station sites are estimated to have as many as 653 charging pads per station in the 80-mile SAEV with Level II infrastructure scenario, down to 43 charging pads per station in the LR SAEV with Level III infrastructure scenario (in order to meet the charging demand of the 5-minute period with the highest number of concurrently charging 
vehicles per day), and their locations represent just $1.8 \%$ of the 1413 trip-active cells, or just $0.0002 \%$ of the 100 -mile by 100 -mile region's 160,000 cells. The total number of actual chargers (charging spaces) needed are approximately $50 \%$ of what was simulated in the NHTS-based trip generation simulation. Such results underscore the fact that charging station locations are a function of both the geography of the service geo-fence and travelers' trip-making patterns.

Finally, a financial analysis of the Austin SAEV scenarios yields operating costs of $\$ 0.386$ to $\$ 0.472$ per occupied-mile traveled, with the 80-mile range SAEVs and Level II charging infrastructure scenario providing the lowest operating costs, which is consistent with findings from the simulated-region's scenarios (as shown in Table 5).

\section{CONCLUSIONS}

Motivated by natural synergies between autonomous driving technology and EVs in a shared setting, this paper employs an agent-based model to simulate the operations of a fleet of SAEVs serving $10 \%$ of all trip demand in a medium-sized metropolitan area under various vehicle and infrastructure scenarios. Simulation results show that fleet size is highly dependent on charging infrastructure and vehicle range. For the non-electric SAV scenario, each shared vehicle can replace 7.3 private vehicles. For a fleet of 80 -mile range SAEVs with a 4 hour full recharge time, this replacement rate drops to one shared vehicle for every 3.7 private vehicles, since more than half of the fleet is tied up in charging activities during any time period. Simulation results also suggest these shared fleets can serve 95.6 to $97.9 \%$ of all trips with average wait times between 7 and 10 minutes per trip, while producing an additional 7 to $14 \%$ of "empty" VMT for traveling to passengers, strategic repositioning, and accessing charging stations. While this induced travel can be reduced slightly with strategic charging, model results also reveal the inherent tradeoffs between reduction of induced "empty" travel and improvement of user experience (as measured by wait times and percent of trips served). These tradeoffs highlight the need for a dynamic pricing scheme for SAEVs which penalizes trips that incur more relocation miles (and thereby increase subsequent trip wait times) and incentivize trips that coincide with strategic relocation (and thereby decrease subsequent trip wait times). A case study using Austin, Texas trip patterns also was used here, to examine the impact of higher concentrations of trips across fewer zones on the service metrics of the SAEV fleet. With more concentrated trip demand, SAEVs traveled similar daily miles, but were able to serve a larger share of trips (over 99\%) with shorter average wait times, ranging from just 2 to 4 minutes. In the Austin case study, "empty" vehicle-miles constitute only 3 to 4 percent of all SAEV travel, and each SAEV could replace 5 to 9 privately owned vehicles, due to somewhat shorter trip distances, as compared to the original simulation.

Financial analysis reveals that despite requiring the largest fleet and the most charging stations, the base 80-mile range SAEV fleet with Level II charging stations is the cheapest to operate on a per-mile basis of all the EV scenarios. This is primarily due to the high sensitivity of per-mile operating costs to vehicle purchase price (with SAEVs assumed to cost $\$ 10,000$ less per vehicle compared to LR SAEVs in the mid-cost scenarios). While SAEVs with Level II charging infrastructure is cost effective, the scenario is ineffective in spreading out charge demand, with as much as $53 \%$ of the fleet concurrently charging during the peak charging period of the day. If SAEVs become a widely adopted mode, this type of fleet can create significant demand on the electric grid and necessitate large parking areas (stations) while charging during peak hours. LR SAEVs with Level III fast charging infrastructure, while costing $14.9 \%$ more per mile compared 
to SAEVs with Level II charging stations, is very effective at demand spreading, with only $7.6 \%$ of the fleet concurrently charging during the peak charging period.

Financial analysis reveals that under the most likely scenario, a fleet of SAEVs can be operated at $\$ 0.41$ to $\$ 0.47$ per occupied mile traveled. The competitiveness of SAEVs compared to nonelectric SAVs hinges almost singly on the availability of automated wireless charging. With wireless automated charging, SAEVs can be price-competitive with SAVs when gasoline is priced at $\$ 3.50$ per gallon or less. But with attendant serviced charging, SAEVs are only price competitive with SAVs when gasoline reaches $\$ 4.35$ to $\$ 5.70$ per gallon.

The agent-based model presented here has limitations that merit improvement in future applications of this type. First, the charging-station generation process mimics the objective of a coverage model (see, e.g., Toregas et al., 1971), thereby ensuring full coverage of all charging demand, but it does not consider budgetary constraints and allows for an unlimited number of charging stations. Additionally, the scenarios modeled here assume that SAEVs will serve 10\% of a region's trip demand and that the temporal and spatial distributions of SAEV trips are the same as the region's overall trip-making patterns. In reality, an SAEV's fleet metrics should be sensitive to trip demand density, over space and time. Additionally, SAEV mode may be more attractive to specific types of trips, rather than be equally appealing for all trips. Chen and Kockelman (2016) explores pricing and operations of a SAEV fleet when competing against other modes (privately-owned manually-driven cars and city bus service) and find that with higher SAEV shares, fleet performance improves. When SAEV mode shares lies between 14 and $39 \%$ (as predicted in the study), private vehicle replacement rates increase to one SAEV for every 10 to 26 vehicles with "empty" VMT constituting 7 to 9 percent of all SAEV travel. That is to say, trips that are more efficiently served by SAEVs are more likely to choose the SAEV mode, which in turn also contributes to improved fleet performance metrics.

\section{ACKNOWLEDGEMENTS}

The authors are very grateful for National Science Foundation support for this research (in the form of an IGERT Traineeship for the first author and Graduate Research Fellowship for the third author), anonymous-reviewers' suggestions, Dr. Daniel Fagnant's provision of the starting code, Prateek Bansal's assembly of Austin's regional trip data, Dr. Peter Stone's editorial guidance, and Dave Tuttle's continued alerts on relevant EV research.

\section{REFERENCES}

AAA (2014). Your Driving Costs: How Much Are You Really Paying to Drive? Available at: http://publicaffairsresources.aaa.biz/wp-content/uploads/2014/05/Your-Driving-Costs-2014.pdf

Anderman, M. (2014). Tesla Battery Report. Advanced Automotive Batteries, September 2014.

APTA (2013) 2013 Public Transportation Fact Book. Available at:

http://www.cfte.org/content_documents/7/2013-APTA-Fact-Book.pdf

Bartlett, J. (2012). Survey: Consumers Express Concerns About Electric, Plug-In Hybrid Cars. Consumer Reports, January 30. Retrieved from: 
http://news.consumerreports.org/cars/2012/01/survey-consumers-express-concerns-aboutelectric-plug-in-hybrid-cars.html

Burns, L., William J., and Scarborough, B. (2013) Transforming Personal Mobility. The Earth Institute - Columbia University. New York.

Chang, D., Erstad, D., Lin, E., Rice, A.F., Goh, C.T., Tsao, A.A., and Snyder, J. (2012) Financial Viability of Non-Residential Electric Vehicle Charging Stations. Luskin Center for Innovation Report, University of California at Los Angeles, August 2012.

Chen, T. D. and Kockelman, K.M (2016). "Management of a Shared, Autonomous, Electric Vehicle Fleet: Implications of Pricing Schemes" Forthcoming in Transportation Research Record.

Douglas, K.W. (2015) “Truly” Empty Vehicle Repositioning and Fleet Sizing: Optimal Management of an Autonomous Taxi System in New Jersey on a Typical Weekday. Bachelors Thesis in Science and Engineering, Princeton University.

EIA (2015) Electric Power Monthly. U.S. Energy Information Administration, March 2015. Available at: http://www.eia.gov/electricity/monthly/epm_table_grapher.cfm?t=epmt_5_6_a

Evatran (n.d.) Plugless Level 2 EV Charging System (3.3KW): Overview and Capabilities. Available at: http://www.pluginnow.com/sites/default/files/PluglessL2_Specs.pdf

Fagnant, D. and Kockelman, K.M. (2014). The Travel and Environmental Implications of Shared Autonomous Vehicles, Using Agent-Based Model Scenarios. Transportation Research Part C Vol (40): 1-13.

Fagnant, D., Kockelman, K.M., and Bansal, P. (2015). Operations of a Shared Autonomous Vehicle Fleet for the Austin, Texas Market. Presented at the $94^{\text {th }}$ Annual Meeting of the Transportation Research Board, Washington, D.C., January 2015.

Federal Highway Administration (2009) National Household Travel Survey. U.S. Department of Transportation. Washington, D.C.

IHS (2014) Emerging Technologies: Autonomous Cars-Not If, But When. IHS Automotive report, January 2014.

International Transport Forum (2015) Urban Mobility System Upgrade: How Shared SelfDriving Cars Could Change City Traffic, OECD Corporate Partnership Report, May 2015.

Knipe, T.J., Gallac, L., Argueta, J. (2003) 100,000-Mile Evaluation of the Toyota RAV4 EV. Southern California Edison Technical Report. Available at: http://www.evchargernews.com/miscfiles/sce-rav4ev-100k.pdf

Kornhauser, A. (2013) PRT Statewide Application: Conceptual Design of a Transit System Capable of Serving Essentially All Daily Trips. Urban Public Transportation Systems 2013: pp. 357-368. 
Litman, T. (2015) Autonomous Vehicle Implementation Predictions: Implications for Transport Planning. Presented at the 2015 Transportation Research Board Annual Meeting (Paper \#153326), January 2015.

Martin, E.W. and Shaheen, S.A. (2011) Greenhouse Gas Emission Impacts of Carsharing in North America. IEEE Transactions on Intelligent Transportation Systems 12(4): 1074-1086.

New York City Taxi \& Limousine Commission (2013) Take Charge: A Roadmap to Electric New York City Taxis. Available at: http://www.nyc.gov/html/tlc/downloads/pdf/electric_taxi_task_force_report_20131231.pdf

New York City Taxi \& Limousine Commission (2014) 2014 Taxicab Factbook. Available at: http://www.nyc.gov/html/tlc/downloads/pdf/2014_taxicab_fact_book.pdf

Plotkin, S. and Singh, M. (2009). Multi-Path Transportation Futures Study: Vehicle Characterization and Scenario Analyses. Argonne National Laboratory Report No. ANL/ESD/09-5. Available at: http://www.osti.gov/energycitations/servlets/purl/968962-2I2Sit/

Rogers, C. (2015) Google Sees Self-Driving Cars on Road within Five Years. Wall Street Journal, January 14. Available at: http://www.wsj.com/articles/google-sees-self-drive-car-onroad-within-five-years-1421267677

Santos, A., McGuckin., N., Nakamoto, Y., Gray, D., and Liss, S. (2011) Summary of Travel Trends: 2009 National Household Travel Survey. Federal Highway Administration Report \#FHWA-PL-11-022. Washington, D.C.

Schultz, C. (2014). Let the Cars Drive Themselves-The Benefits of Autonomous Vehicles on Socioeconomics. Master's Thesis, University of Gothenberg.

Shaheen, S., Cohen, A. and Roberts, J.D. (2006) Carsharing in North America: Market Growth, Current Developments, and Future Potential. Transportation Research Record 1986, pp. 116124.

Spieser, K., Ballantyne, K., Treleaven, K., Zhang, R., Frazzoli, E., Morton, D., and Pavone, M. (2014). "Toward a Systematic Approach to the Design and Evaluation of Automated Mobilityon-Demand Systems: A Case Study in Singapore.” In G. Meyer and S. Beiker (Eds.), Road Vehicle Automation: Lecture Notes in Mobility (pp. 229-245). Switzerland: Springer International Publishing.

Tannert, C. (2014) Will You Ever Be Able to Afford a Self-Driving Car? Fast Company, January 13. Available at: http://www.fastcompany.com/3025722/will-you-ever-be-able-to-afford-a-selfdriving-car

Toregas, C., ReVelle, C., Swain, R. and Bergman, L. (1971) The Location of Emergency Service Facilities. Operations Research (19), pp. 1363-1373. 
657 US Department of Energy (2012) Plug-In Electric Vehicle Handbook for Public Charging 658 Station Hosts. DOE/GO-102012-3275, April. Available at:

659 http://www.afdc.energy.gov/pdfs/51227.pdf

660 Wang, F., Yang, M., and Yang, R. (2006) Dynamic Fleet Management for Cybercars.

661 Proceedings of the IEEE Intelligent Transportation Systems Conference, Toronto, Canada. 